تأثير عملية الالمتة على تتابعات تكوين ميركي (سينومينيان - التوروني المبكر)

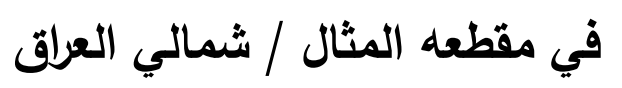

$$
\begin{aligned}
& \text { ابراهيم سمير العكلي }
\end{aligned}
$$

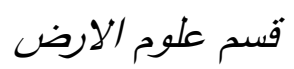

$$
\begin{aligned}
& \text { كلية العلوم } \\
& \text { جامعة الموصل }
\end{aligned}
$$$$
\text { رافع ابراهيم الحميدي }
$$$$
\text { قسم علوم الارض القميل }
$$$$
\text { كلبة العلوم }
$$$$
\text { جامعة الموصل العومل }
$$

$$
\text { ( تاريخ الاستلام 2014/1/15 ، تاريخ القبول 2014/3/23 ) }
$$

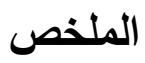

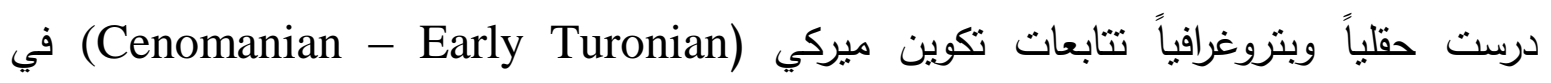
منكثفات مقطعه المثال في شمالي العراق (48) متراً، بهرف استقراء تأثير عمليات الدلمتة فيها. وقد نبين

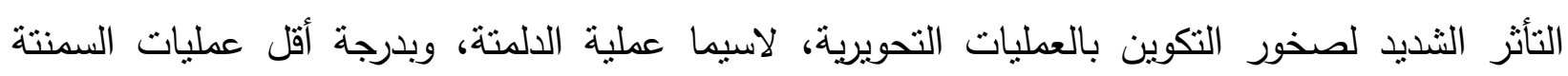
والإذابة والمكرتة والانضغاط بنوعيه الفيزيائي والكيميائي. تظهر بلورات الدولومايت في صخور التكوين

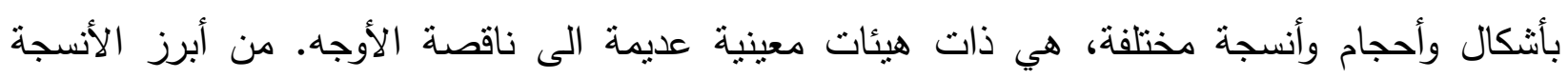

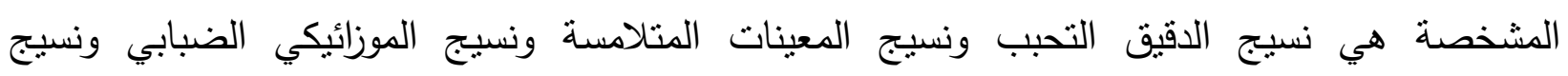

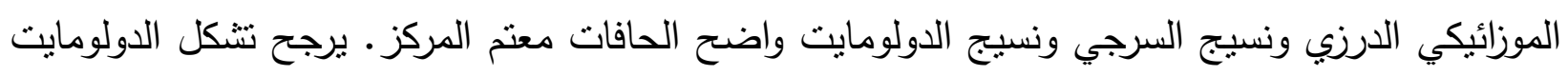
في هذه الصخور بآلية الخلط والدلمتة التحت السطحية المتأخرة (الدفن لعميق). الكلمات الدالة: الدلمتة، تتابعات، ميركي، سينومينيان، التوروني المبكر .

\section{The Effect of Dolomitization on Mergi Formation Sequences (Cenomanian- Early Turonian ) at The Type Section, Northern Iraq}

Rafi I. AL-Homadi

Department of Geology

College of Science

University of Mosul
Ibrahim S. Al-Okli

Department of Geology

College of Science

University of Mosul 


\section{ABCTRACT}

In order to study the effect of dolomitization on Mergi Formation sequences (Cenomanian - Early Turonian), Field and petrographical examinations were carried out on fourty six meters $(46 \mathrm{~m})$ of the type section of this formation. It has been observed that the formation is highly affected by diagenesis processes, especially dolomitization. On the other hand, the effects of other processes such as. cementation, dissolution, micritization and compaction in its both types, physical and chemical were less than dolomitization. Dolomite crystals appeared as rhombshaped euhedral to subhedral. The main diagnosed fabrics were Aphanotopic, Contact-rhomb porpherotopic, fogged mosaic, Sutured mosaic, Saddle dolomite and Cloudy-centered clear-rimmed dolomite fabrics. It is concluded that formation of dolomite was by the mechanism of mixing zone model and subsurface dolomitization model.

Keywords: Dolomitization, Mergi, Sequences, Cenomanian, Early Turonian.

\section{المقدمة}

تقع منطقة الدراسة شمالي العراق على بعد (48Km) شمال غرب محافظة دهوك، حيث المكثف

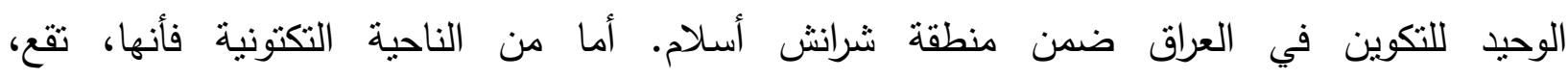

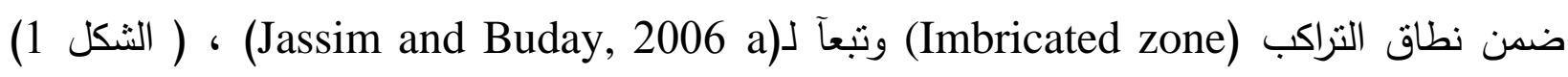

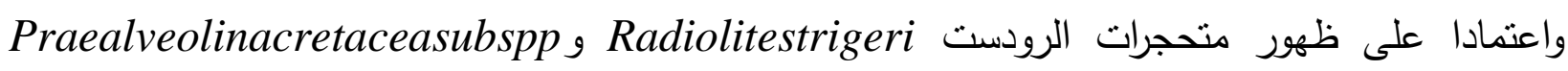

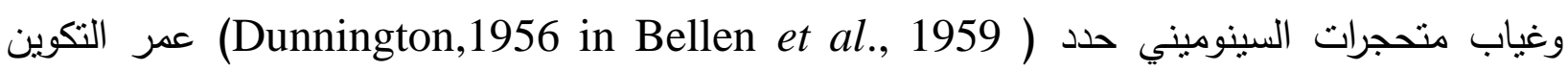
بالتوروني. أما (Chattonand Hart,1961)، فقد أثنارا الى ان تكوين ميركي يعود اما الى دورة

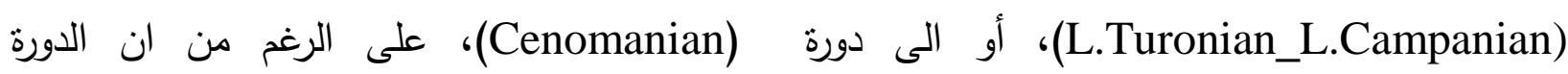

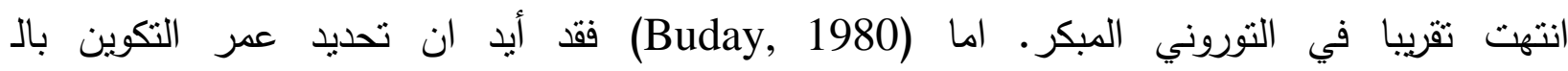
(Jenomanian_Early Turonian) فأن المرجح أن عمر النكوين هو (Cenomanian - Early Turonian). وصف (Dunnington,1956 in Bellen et al., 1959) التكوين لأول مرة في منطقة شرانش في شمالي العراق، حيث يقع المقطع المثال على بعد حوالي 850 مثر من قرية شرانش أسلام على الجانب

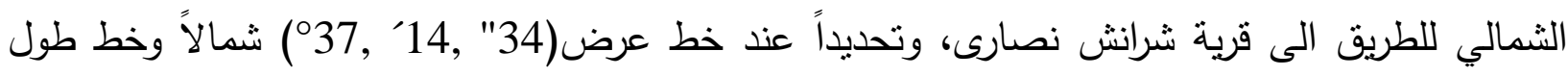

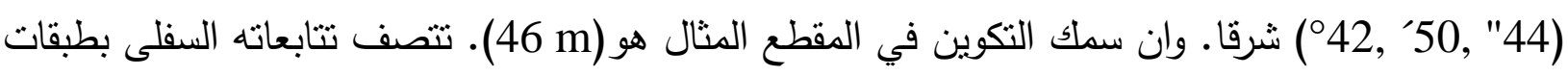

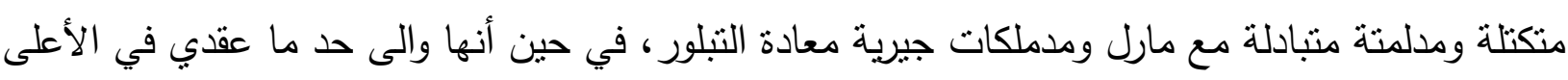

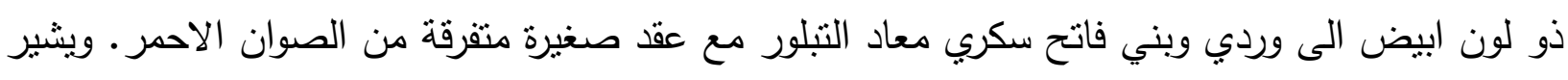
(Chatton and Hart1961) 
اجزاء من حزام جبال زاكروس الإيرانية، إلا أن منل هذه الترسبات لم تظهر في نطاق العراق، باستثناء أحدى

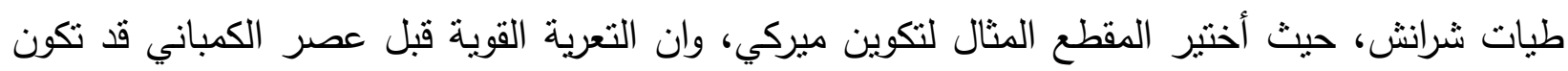
هي التفسير لغياب تكوين ميركي في المناطق الاخرى من العراق، إذ يعتقد أن هذه الوحدة كانت واسعة

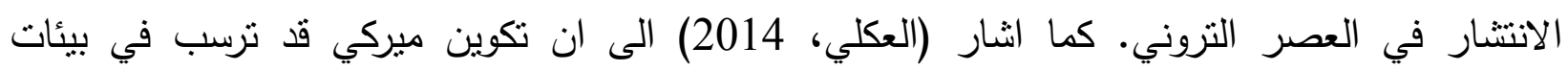

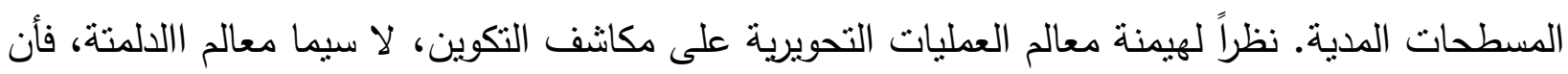
الدراسة الحالية تهدف الى تسليط الضوء على هذه العملية وذلك بالأعتماد على الدلائل الحقلية والبتروغرافية

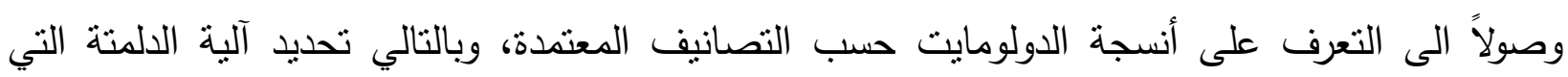
هيمنت على صخور التكوين.

\section{طETHODOLOY طرائق البحث}

تنتلت الدراسة الحقلية بالوصف الدقيق للمقطع الصخري المنكثف، متضنفاً الوصف الصخري الدقيق

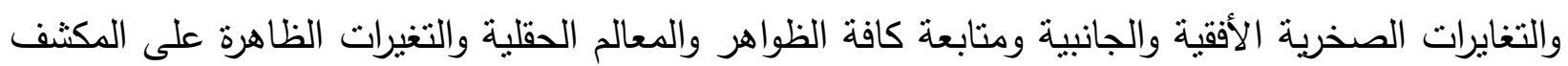

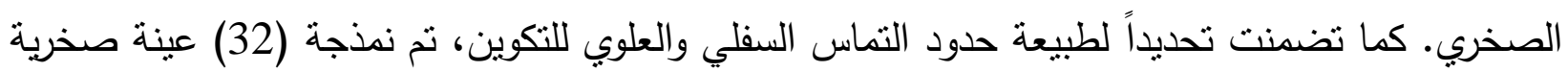
لغرض تهيئة الثرائح الرقيقة الخاصة لنتخيص المكونات البتروغرافية والعمليات التحويرية المؤثرة فيها،

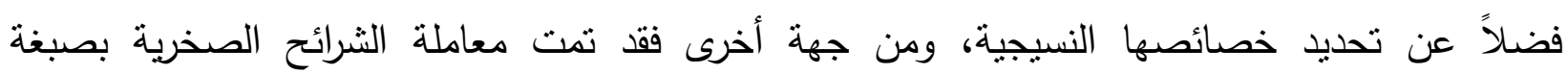
الاليزيرين الحمراء (Alizeren red staining)، وحسب طريقة ( Dickson,1965)، لغرض تميز فئ معدن الكالسايت عن معدن الدولومايت. تم أختبار ثمان عينات موزعة على طول المقطع الصخري، لتحليلها

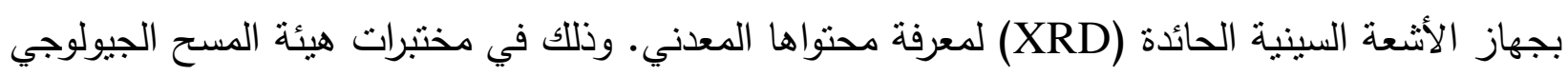
العراقية / بغداد. 
رافع ابراهيم الحميدي و ابراهيم سمير العكلي

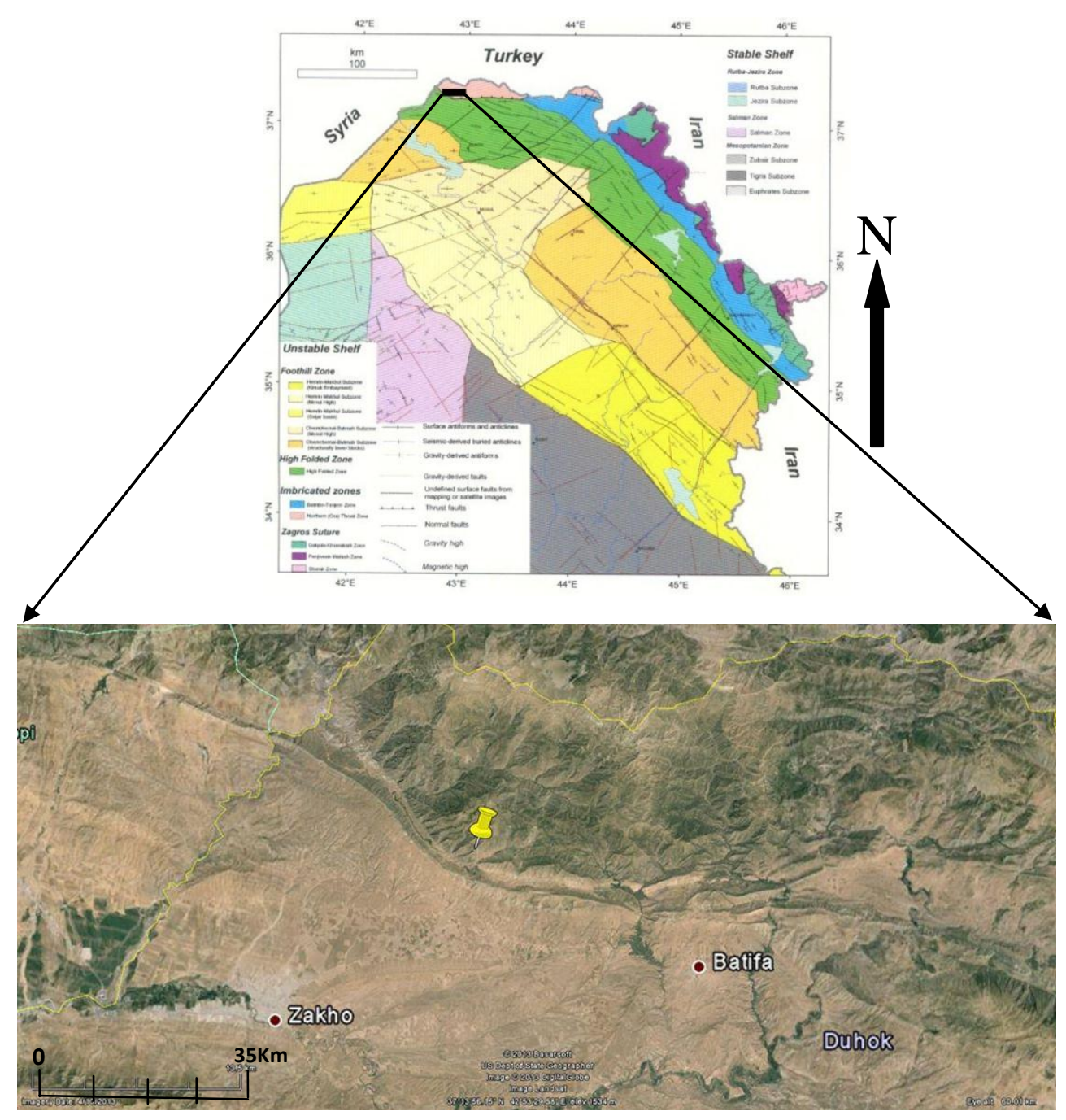

الشكل 2 : خارطة تكتونية لنمالي العراق (Jassim and Buday, 2006a)، وصورة

مرئية فضائية توضح منطقة الدراسة ( Google Earth, 2013 (

\section{الطباقية: Stratigraphy}

تتكثف تتابعات تكوين ميركي في منطقة شرانش أسلام، بسمك (48 m) تقربياً، تحدها من الأسفل وبصورة غير منوافقة تتابعات تكوين قمجوقة، أذ تتجلس ترسبات نكوين ميركي بصورة مباشرة فوق طبقة جيرية معادة التبلور ذات حصوات جيرية رمادية فاتحة اللون معادة التبلور، أما تتابعات تكوين ميركي ميري المتجلسة فوق هذه الطبقة فهي مؤلفة في جزئها السفلي من طبقة جيرية متدلمنة هشة رمادية غامقة اللون (2m)، حاوية على تراكيب الستروماتولايت، ثم تليها طبقة من الدولومايت المصدت المطعم بعروق الدولومايت النقي الأبيض اللون (Saddle) ذات لون رمادي غامق يصل الى سمكها حوالي المترين، تعلوها طبقة من الدلومايت المصمت السكري الرمادي الفاتح الى المبيض أحياناً (5.5m)، تليها طبقة من 
الدولومايت المصمت ذات لون الرمادي الغامق الحاوي على عروق من الدولومايت الأبيض النقي بسمك

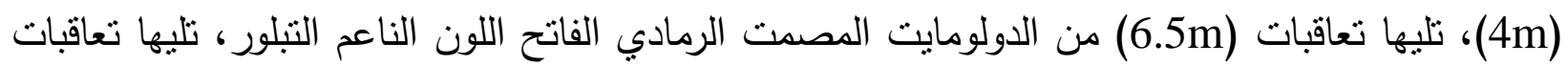
من الدولومايت المصمت (6m) الرمادي الغامق الحاوي على عروق من الدولومايت النقي الابيض، تليها

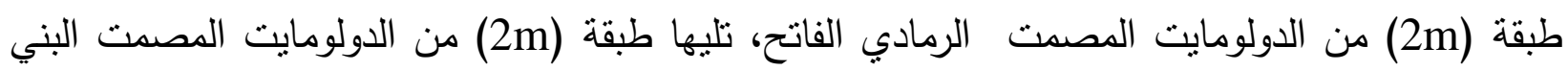

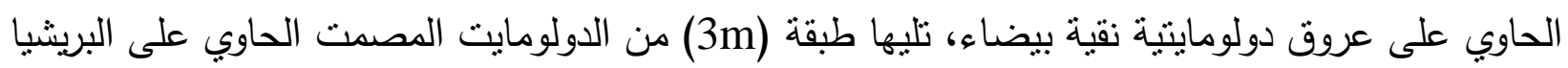

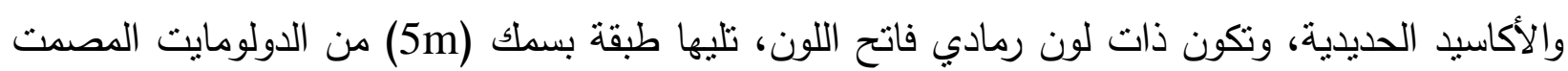

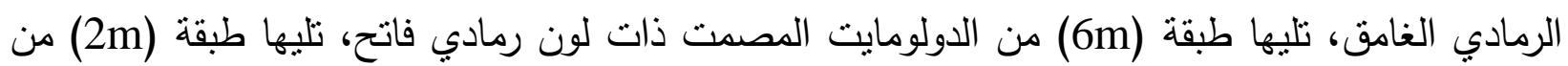
الدولومايت الدصت الرمادي الحاوي على عروق الدولومايت النقي الابيض، وتختتم هذه التتابعات بطبقة (2m) من الدولومايت المصدت البني المحمر، تعلوها بصورة غير منوافقة طبقة من الدملكات القاعدية

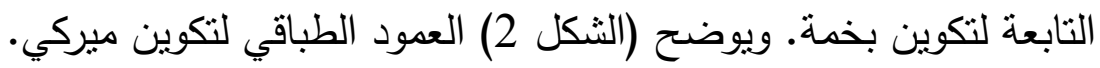

\section{الاراسة البتروغرافية: Petrography study}

أظهرت الدراسة البتروغرافية التأثر الثديد لعموم مكونات الصخور الجيرية بالعطليات التحويرية. وتعد

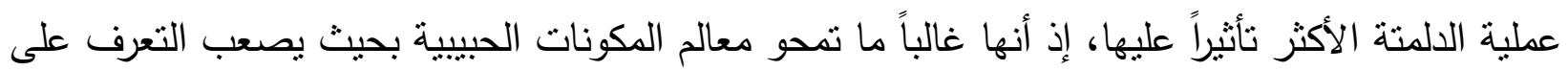
عائديتها. فضلاً عن تأثير الدلمتة على هذه الصخور فأنها متأثزة بعمليات تحويرية أخرى مثل السمنتة

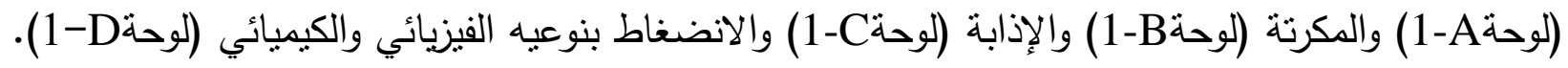

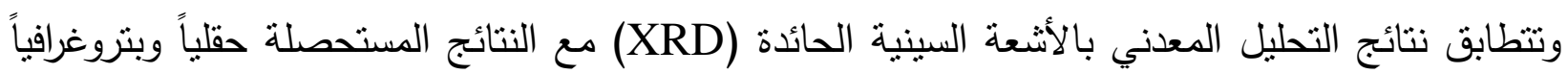
من حيث هيمنة الدولومايت على ترسبات النكوين (الثكل 3).

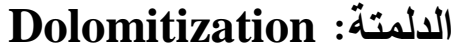

تعتبر الدلمتة من العمليات التحويرية غير المتماتلة كيميائياً وتتم من خلال إحلال أيون المغنيسيوم محل أيون الكالسيوم (Mg $\left(\mathrm{Mg}^{+2}\right)$

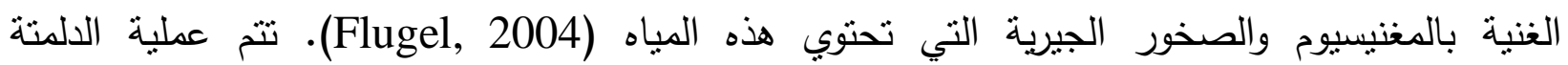
بتأثيرات المياه البحرية او القارية وفي أنطقة ذات مياه مختلطة اي مناطق أمنزاج المياه العالية الملوحة مع العاعيه

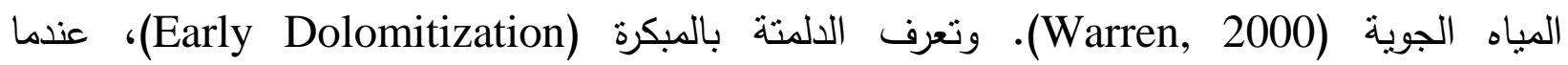
يحدث الإحلال بعد عملية الترسيب بفترة قصيرة او قبل تصلب الصخور او تعرف بالدلمتة المتأخرة

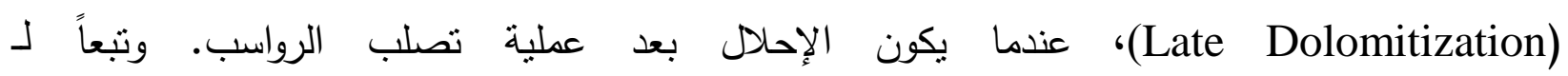
.(Flugel, 1982; Atabey, 1995) 


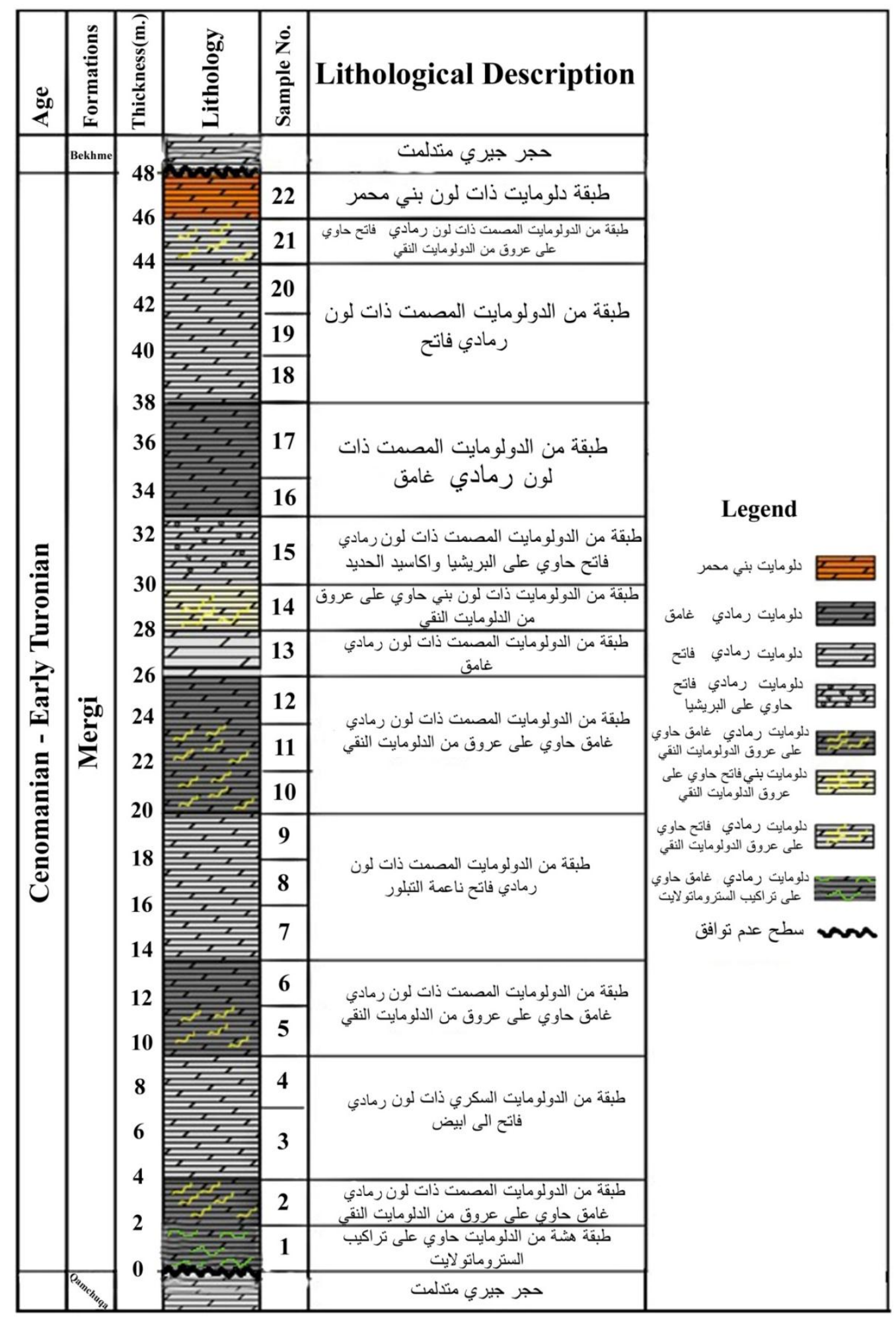

$$
\text { الثكل 2: يوضح العدود الطباقي لتكوين ميركي. }
$$


تأثثير عملية الدلمتة على تتابعات تكوين ميركي (سينومينيان - التوروني المبكر) في مقطعه.
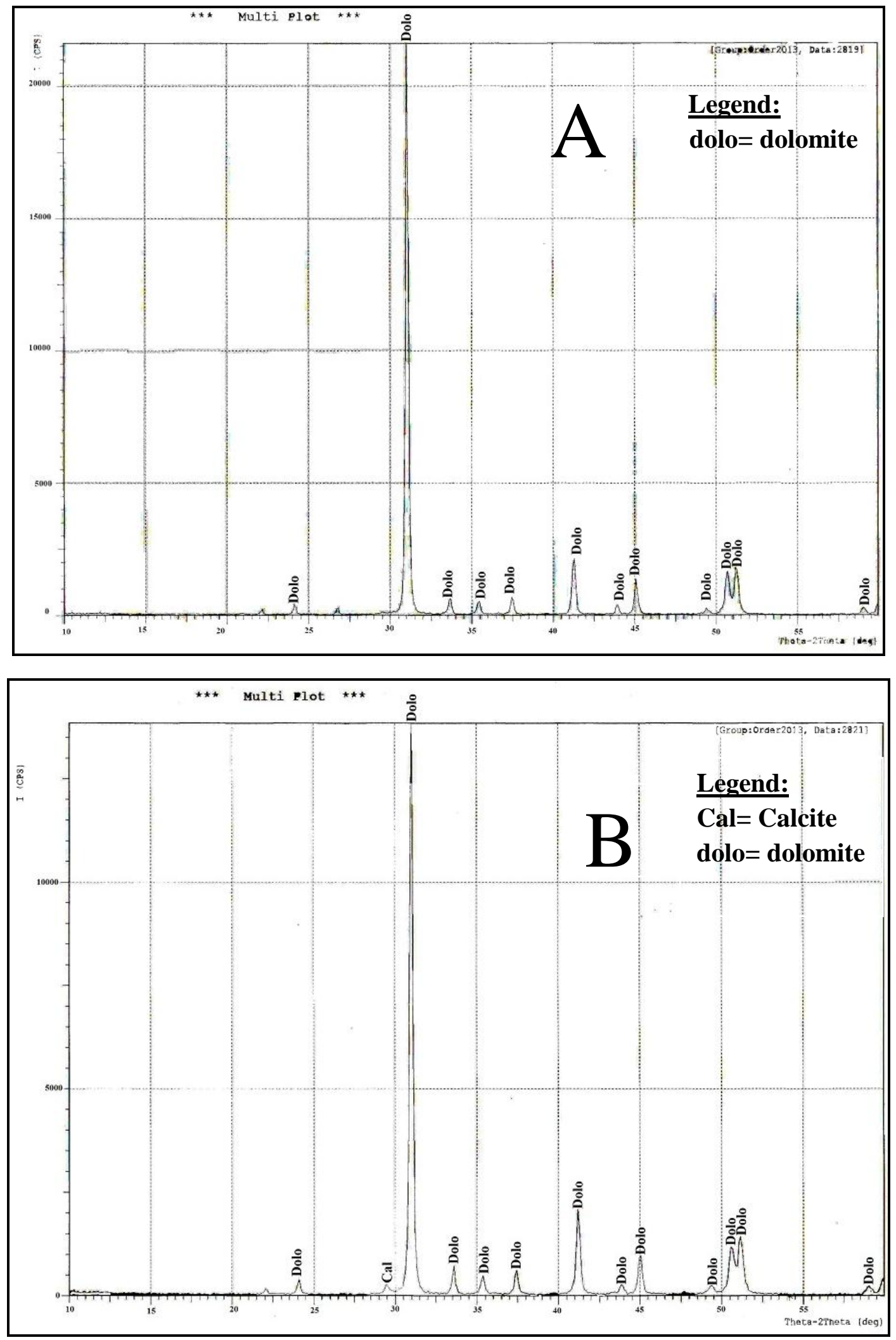

الثكل 3: يمثل مخططات(XRD)- يمثل مخطط لنموذج مأخوذ من الجزء العلوي لتكوين ميركي. B- يمنل مخطط لنموذج مأخوذ من الجزء السفلي لتكوين ميركي. 


\section{تصنيف أنسجة الالومايت: Classification of dolomite fabric}

تتكون صخور تكوين ميركي أساساً من معدن الدولومايت، حيث تظهر بلورات الدولومايت

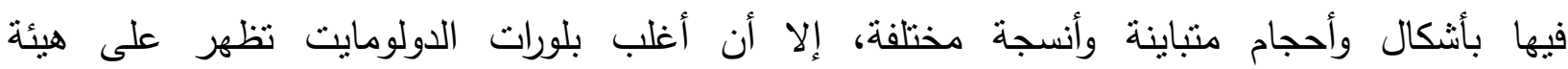

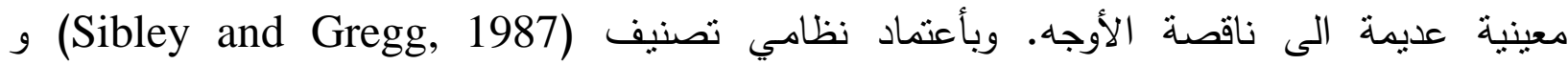

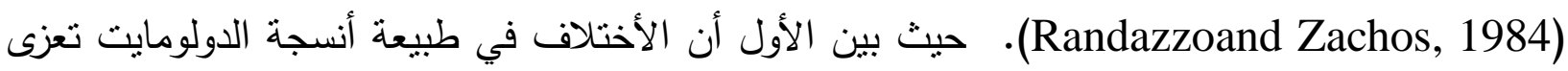

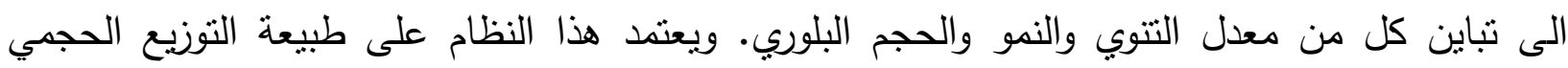

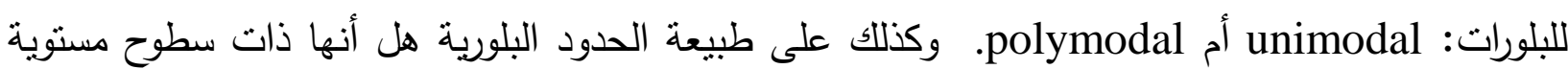
planar Nononplanar للتعبير Idiotopic. فيما يقسم التصنيف الثاني (Randazzo and Zachos, 1984) (الثكل 4) والذي درافي يعد أكثر شمولية من ناحية تصنيف صخور البحث، والتصنيف يقسم انسجة الدولومايت الى ثلاث مجاميع رئيسة والتي بدورها تتضمن عدة مجاميع ثانوية. ويعتمد هذا النظام على شكل البلورات وحجمها

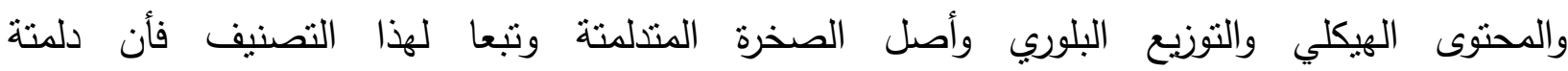
لصخور تكون أما دلمتة غير متجانسة (Heterogenousdolomitization) وتحصل ولتهل عبر مراحل متعددة أو دلمتة متجانسة (Homogenous dolomitization) تحصل بمرحلة واحدة. ومن الأنسجة المشخصة في الصخور الكاربوناتية لنكوين ميركي تبعاً لنظامي (Gregg andSibley, 1984) و) (Randazzoand Zachos, 1984) هي كالأتي: 1- النسيج الدقيق التبلور: Aphanotopic Fabric يعود هذا النسيج الى الهجموعة النسيجية الاقيقة التحبب ، فهو يتميز ببلوراته الدقيقة الحجم

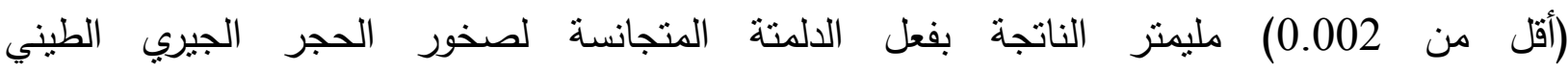

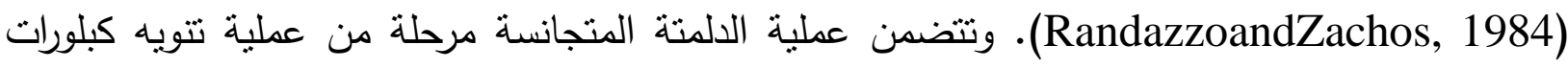

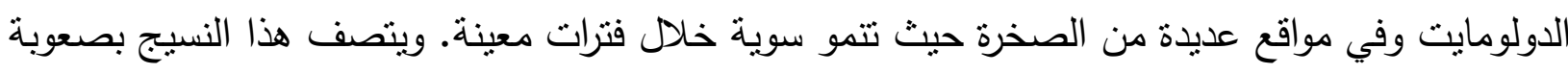

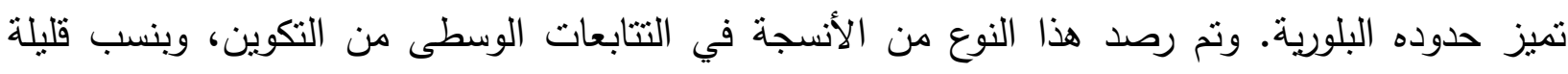

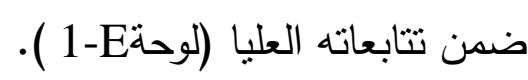

2- نسيج المعينات المتلامسة: Contact-Rhomb Porphyrotopic Fabric يتتكل هذا النسيج من تلامس بلورات الدولومايت العديمة الأوجه الى شبه كاملة الأوجه. ويعود هذا

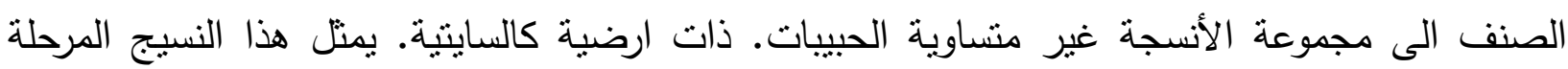

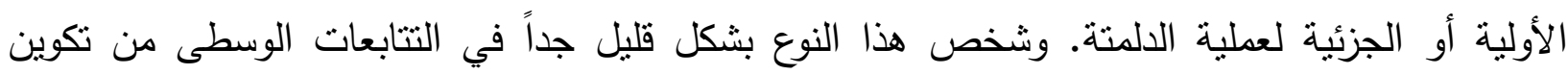

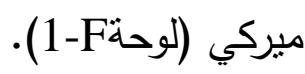




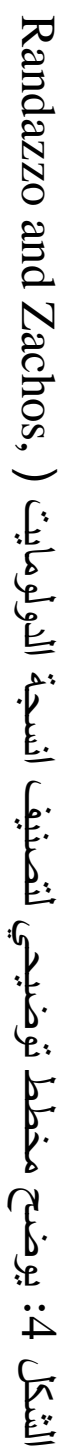
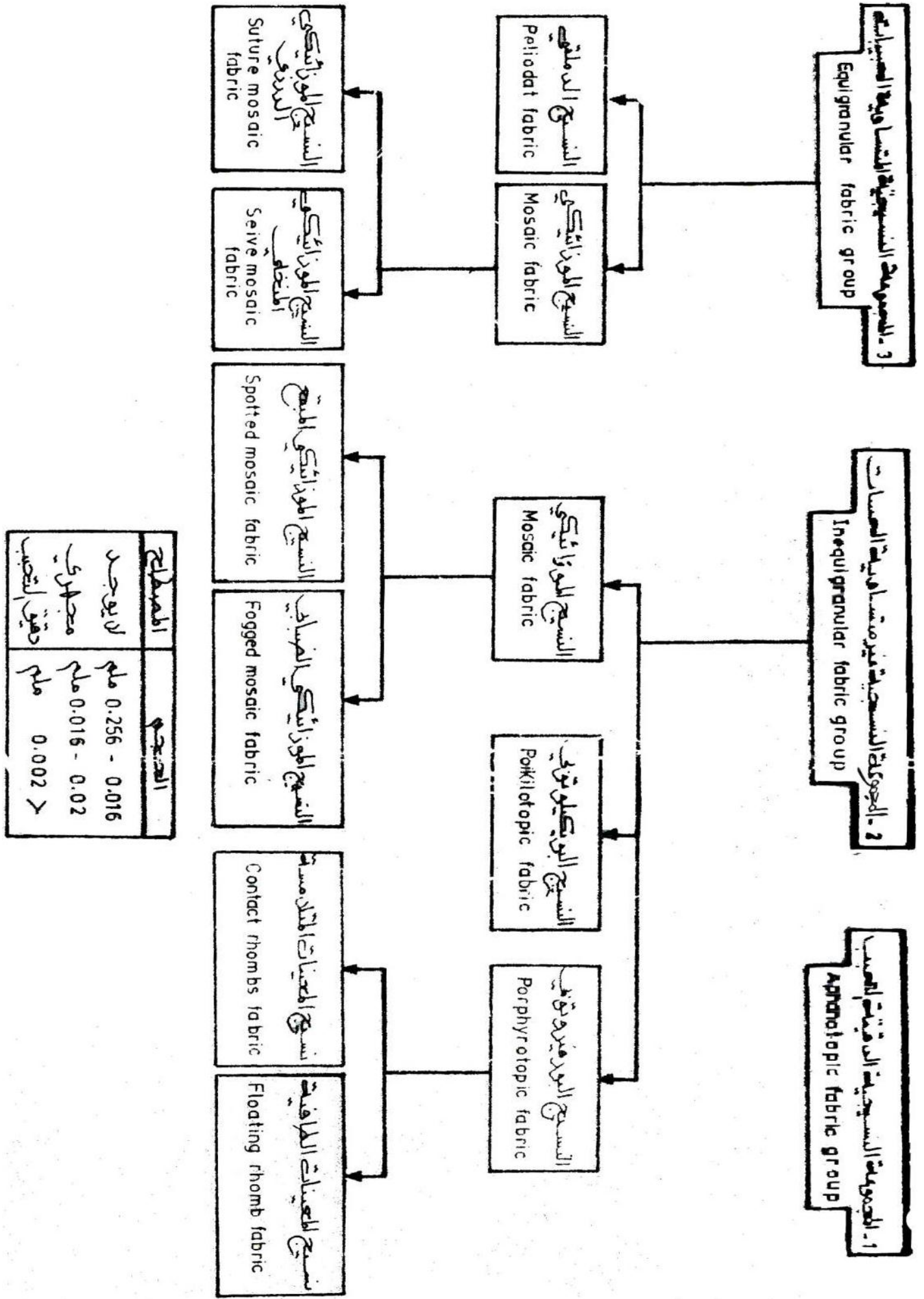

3- النسيج الموزائيكي الضبابي: Fogged Mosaic Fabric

هو من المجموعة النسيجية غير منساوية الحبيبات يتميز بوجود بلورات دقيقة ذات مبعثرة في وسط أرضية مؤلفة من بلورات دولومايتية كبيرة الحجم. ويعبر عنه كنسيج موزائيكي يحتوي بداخله على تجمعات حبيبة ضبابية غير مشخصة الأصل في الأغلب. ويعزى نشوء هذا النسيج الى عمليات الدلمتة غير 
المتجانسة. يظهر هذا النسيج وبشكل قليل في التتابعات السفلى من التكوين، إلا إنه يزداد نوارداً في

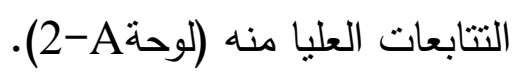

4- النسيج الموزائيكي الدزي: Sutured Mosaic Fabric يتألف هذ النسيج من بلورات دولومايتية عديمة الى ناقصة الاوجه متراصة بأحكام ذات مسامية قليلة

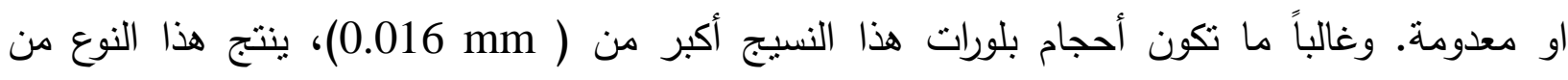

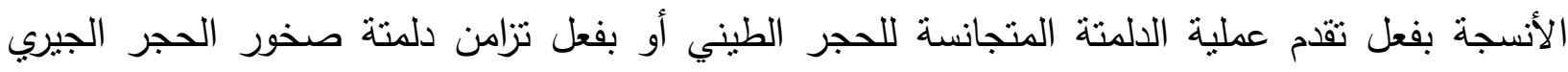
الواكي أو المرصوص مع إذابة مكوناتها الهيكلية (RandazzoandZachos, 1984). وممكن الأشارة إلى لفى لفئة

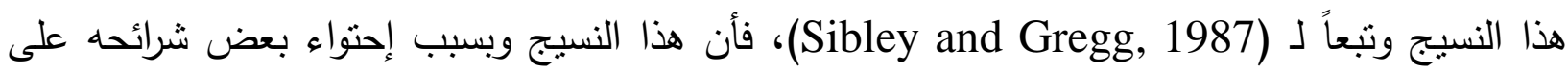
بلورات ناقصة الاوجة فأنها تعرف بـ(Hypidiotopic texture)، في حين تسمى البلورات عديمة الاوجه

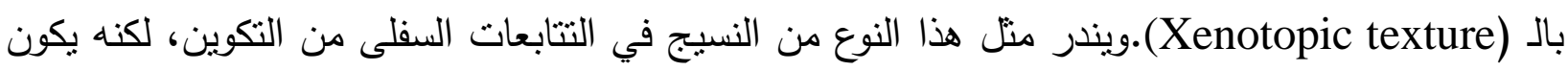

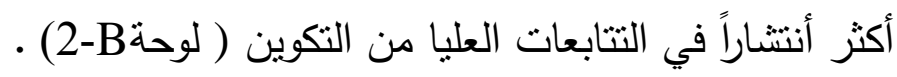

5addle Dolomite النسيج السرجي: Sa

يتألف هذا النسيج من بلورات الدولومايت بهيئة سرج أو باروكي وأحياناً منل رمح معقوف بسبب التواء التركيب البلوري وتكون البلورات ذات إنطفاء متموج. وهذا النسيج عبارة عن بلورات دولومايتية سمنتية مالئة للفراغات (Flugel, 2004; Sibley and Gregg, 1987). ويشير هذا النسيج إلى مراحل الدلمتة المتأخرة (Shingaly et al., 2013) (لوحةC-C) ويكون بالقرب من خطوط الإذابة الستايلولايت.

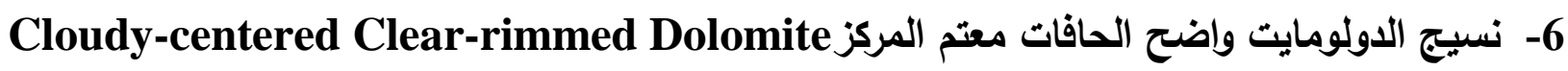
ينألف هذا النسيج من بلورات الدولومايت متراصة بشكل موزائيكي، وهي عادة على هيئة معينات

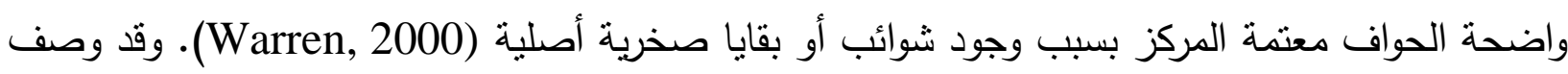

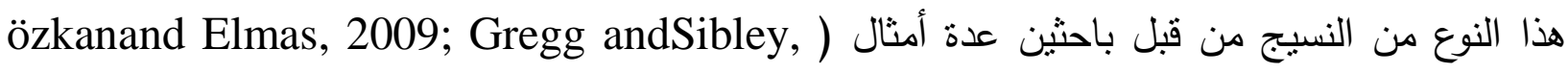

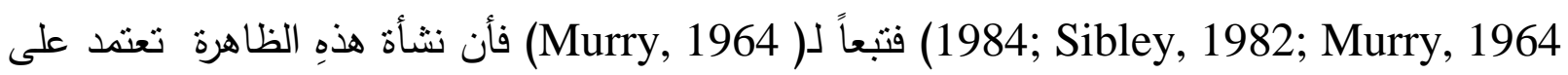

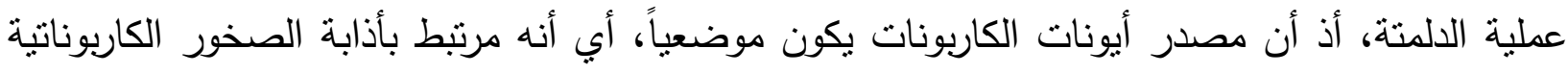

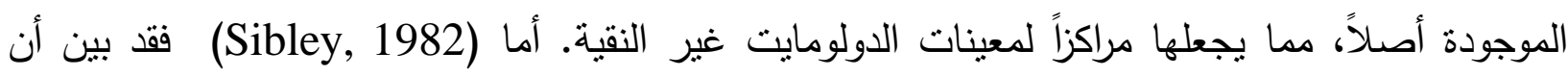

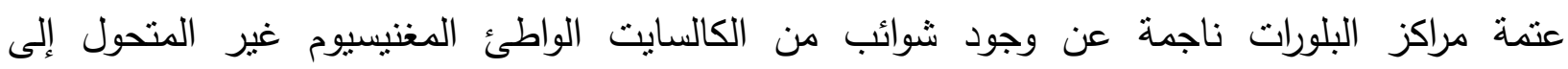

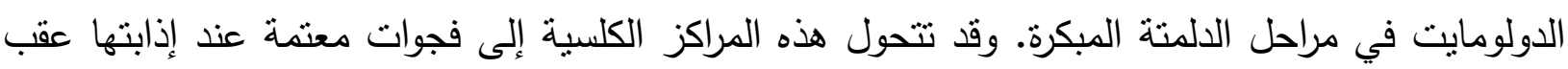

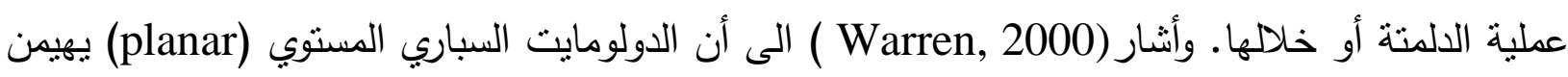

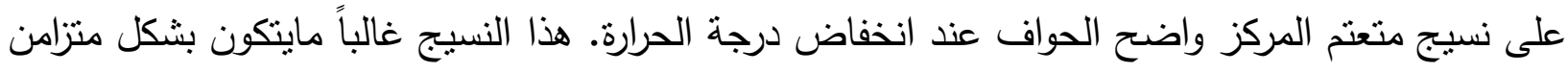
مع عملية الدلنة أو في وقت مبكر بعد عملية ترسيب الدولومايت، في حين تتنج الحافات الواضحة النقية 
بفعل النمو المتواصل خلال العمليات التحويرية المتأخرة (Rameil, 2008). ولوحظ من خلال دراسة

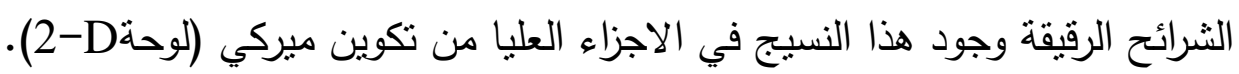

موديلات الدلمتة: Dolomitization Model

هناك العديد من النظريات والموديلات المقترحة من قبل العلماء لتفسير عملية الدلمتة. أذ تبين من

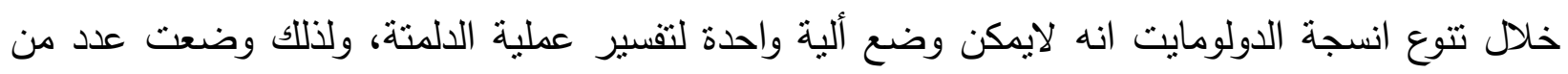

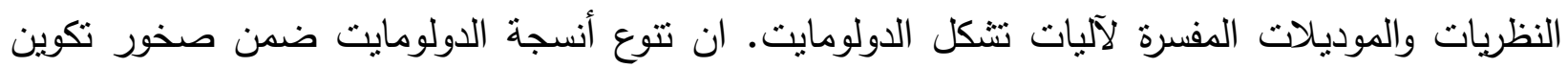

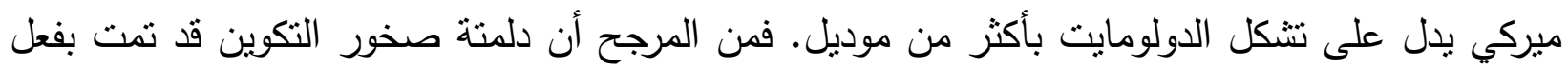

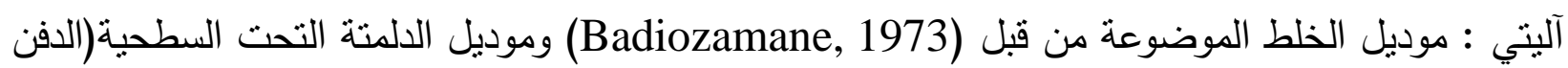
لعميق) الموضوعة من قيل (Illing et al., 1965). وفيما يأتي اهم مديزات كل موديل ودلائلها في صخور

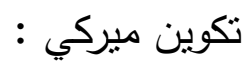

\section{1- موديل المزج: Mixing Zone Model}

يعد موديل المزج من الموديلات المهمة التي تفسر عملية الدلمتة لأكثر من ثلاث عقود من الزمن في

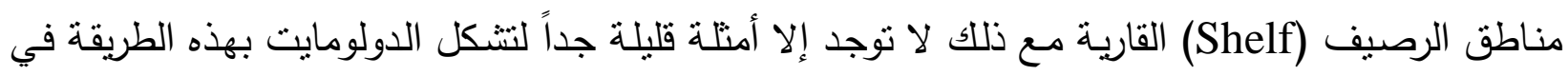
الرواسب الحديثة (Flugel, 2010; Warren, 2000). تعزي هذه النظرية سبب حدوث الدلمتة الى أمثزاج المياه البحرية مع المياه العذبة او جوية (Meteoric water) بنسبة(5-30\%) محققة بذللك البيئة الملائمة للالمتة (Badiozamane, 1973; Ward and Halley, 1985)، إذ أن المياه العذبـة المشبعة بغاز (CO ${ }^{2}$ الدذاب تتتج عند امتزاجها مع مياه البحر خليطاً من المياه القادرة على أحلال المغنيسيوم بدل

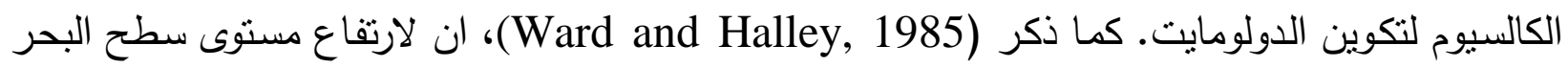

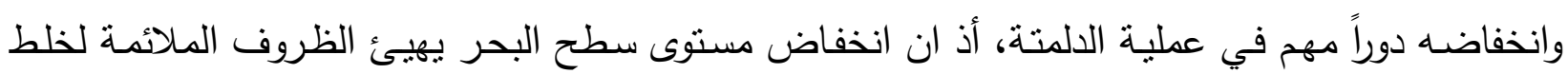

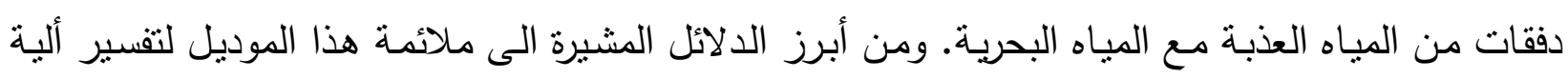

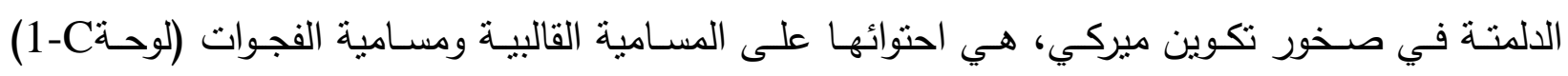
والسمنت البلوكي والدروزي (لوحة A-A) وعملية المكرتة (لوحة B-1-1) والمنطورة جميعها بوجود المياه العذبة العبة

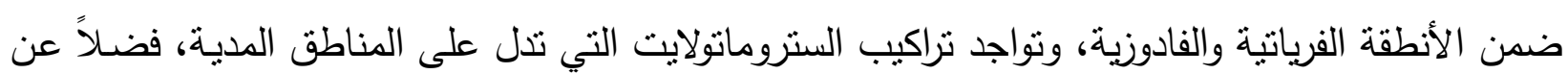
عدم ترافق المتبخرات مع عملية الدلمتة. 2- موديل الالمتة تحت السطية modelSubsurface dolomitization أقترح هذا الموديل والذي يعرف أيضاً موديل ضغط الدفن (Burial Compaction) من قبل

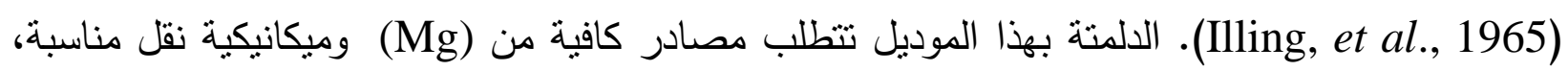

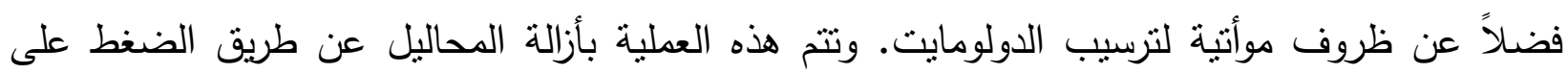

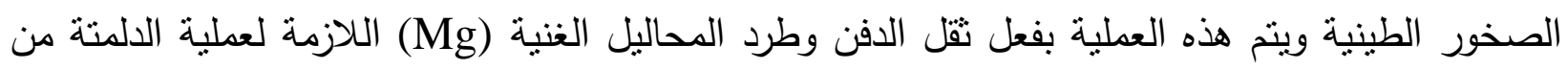


المياه المسامية وذلك بالتزامن لتحول المعادن الطينية الاسمكتايت الى الألايت الناجم عن زيادة العمق

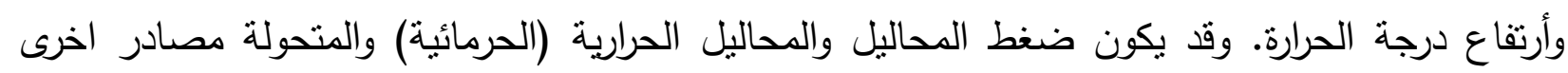

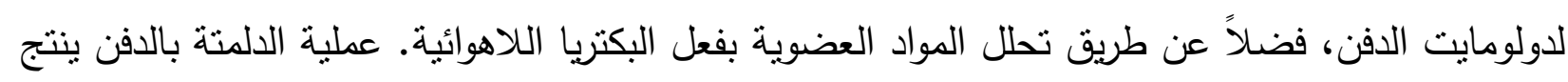

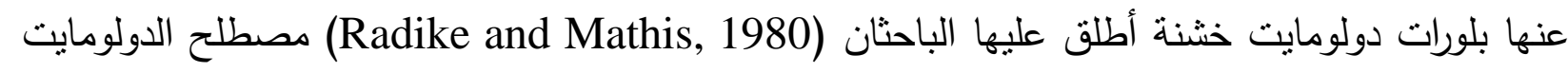
السرجي (Saddle dolomite) وغالباً مايكون على شكل بلورات بيضاء حليبية خشنة منكونة في داخل المسامات القالبية والفجوات (Flugel, 2010; Warren, 2000). ولعدم وجود مصدر قريب للاطيان بكميات كبيرة وعدم وجود اثنار للهيدروكاربونات، فمن المرجح تكون الدولومايت السرجي عن طريق الترسيب

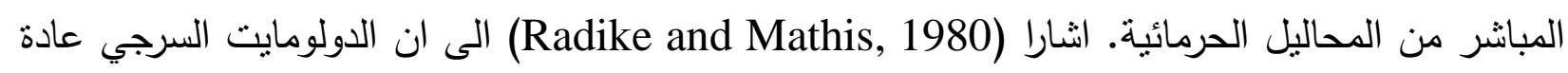

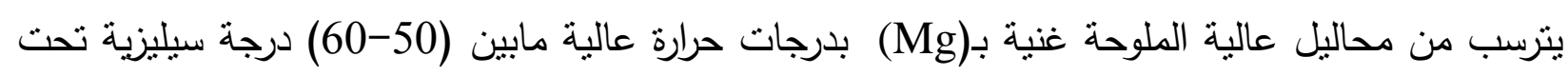
السطح. اتضح مجهرياً أن أغلب مظاهر الدلمتة في تكوين ميركي تدل على موديل الدلمتة تحت السطحية.

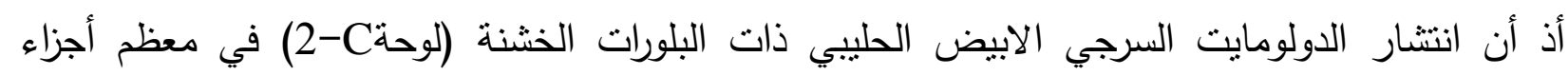

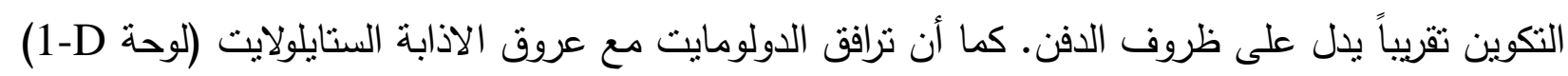

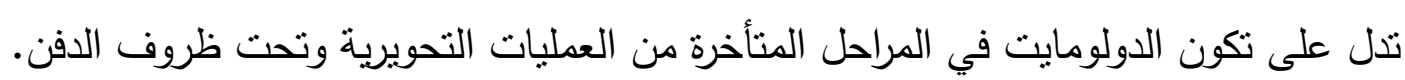

\section{الأستنتاجات}

الفحص الحقلي والدراسة المعدنية والمجهري الدقيقة أفرزت عدة نتائج ومن أبرزها ما يأتي:

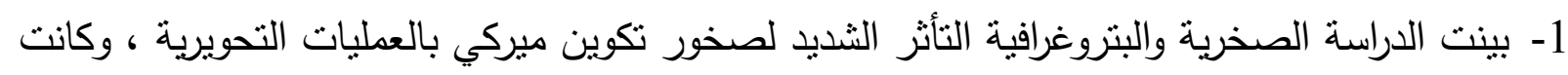

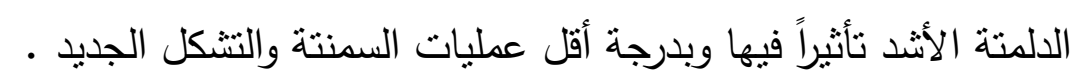

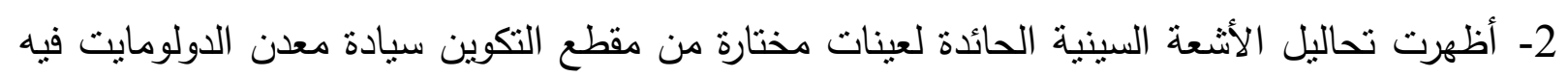
المقارنة بمعدن الكالسايت.

3- أعتماداً على تصنيفي (Sibley and Gregg, 1987) و (RandazzoandZachos, 1984) لأنسجة الدولومايت فأن الأنسجة المشخصة في الصخور الدولومايتية لتكوين ميركي هي نسيج الدقيق التحبب، نسيج المعينات المتلامسة، نسيج الموزائيكي الضبابي، نسيج الموزائيكي الدرزي، نسيج الأبيج

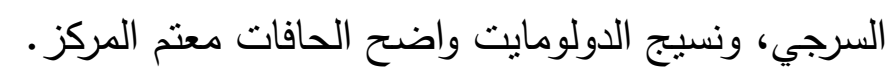

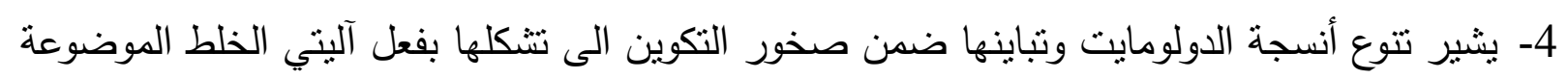
من قبل (Badiozamane, 1973)، والدلمتة تحت السطحية (الدفن العميق) الموضوعة من قبل فيل فئل

.(Illinget al., 1965) 

تأثثر عملية الدلمنة على نتابعات تكوين ميركي (سينومينيان - التوروني المبكر ) في مقطعه.

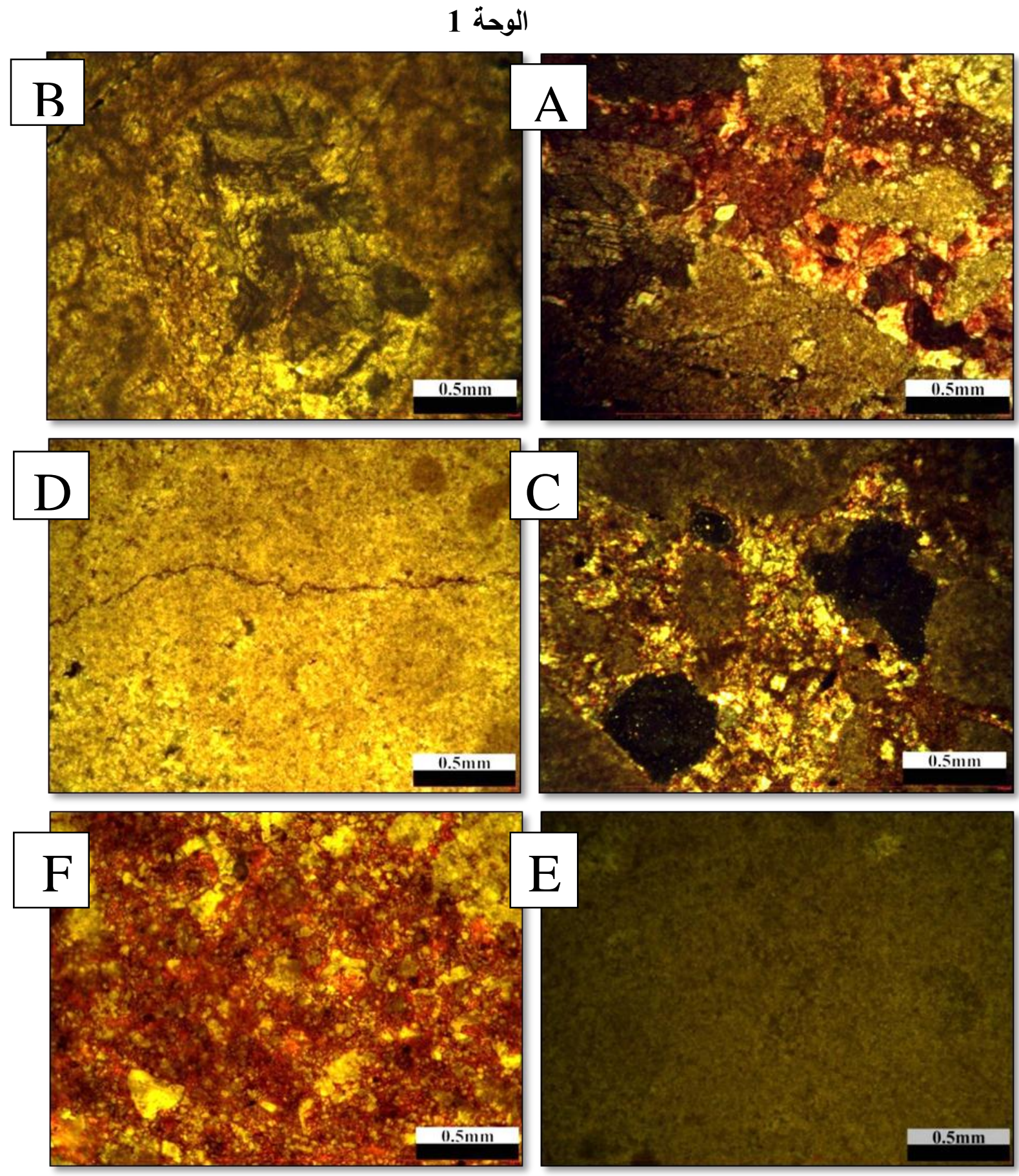

$$
\text { A }
$$

B صورة توضح صدفة متحجرة محاطة بغلاف مكرايتي.

C صورة توضح عملية الإذابة ومسامية الفجوات.

D. صورة توضح الستايلولايت نتيجة الانضغاط الكيميائي.

$$
\text { E }
$$

F 


$$
\text { رافع ابراهيم الحميدي و ابراهيم سمير العكلي }
$$

\section{الوحة 2}

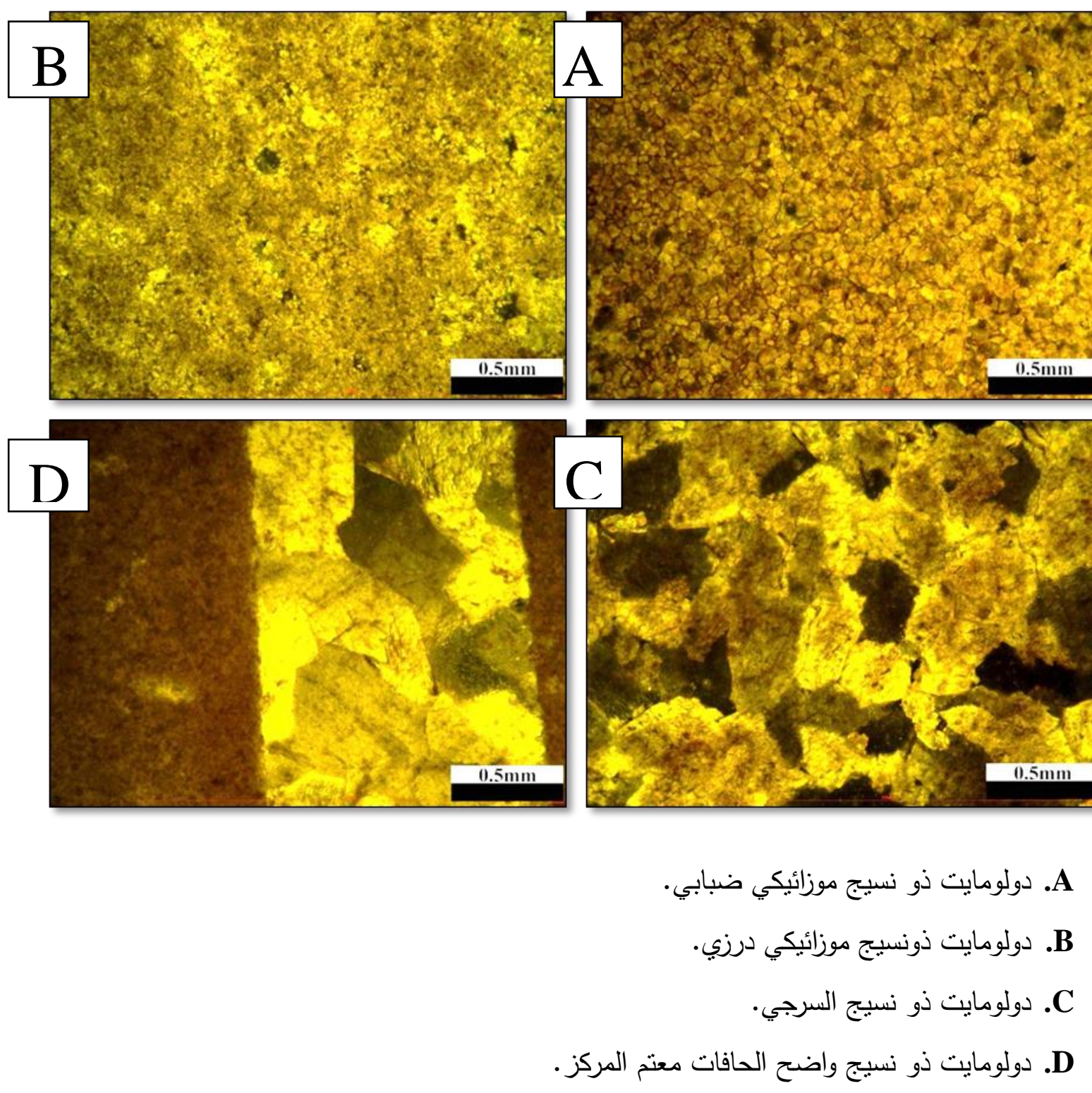

\section{المصادر العربية}

العكلي، ابراهيم سمير 2014. دراسة رسوبية لتكوين ميركي (سينومينيان - التوروني المبكر) في مقطعه المثال شمالي العراق. رسالة قيد المناقثة. 


\section{المصادر الاجنبية}

Atabey, E., 1995. Petrography and origin of dolomite of Yaniktepe Formation Upper Cretaceous in Gurunautochtonous Eastren Taurus Turkey, Mineral Res. Expl. Bull, Vol. 177, pp. 59 - 67.

Badiozamani, K 1973. ThaDoragdolomitization model-application to the Middle Ordovician of Wisconsin Jounrnal of Sedimentary Petrology, Vol. 43, pp. 965 - 984 .

Bellen, V.R.G., Dunnington, H.V., Wetzel, R. and Morton, D.M.,(1959): Lexique

Stratigraphic International. V.3, Asie Fascicule loa-Iraq. Paris, 333p.

Buday, T., 1980. The Regional Geology of Iraq, Stratigraphy and Paleogeography.

Dar Al-Kutub publishing house, Mosul University. Mosul, Iraq, 445p.

Chatton, M. and Hart, E. 1961 Review of the Cenomanian to Maestrichtian stratigrpahy in Iraq. Unpublished report, Iraq Petroleum Company, Palaeontological Department, Kirkuk.

Dickson, J. A., 1965. Carbonate identification and genesis as revealed by staining, ournal of Sedimentary Petrology, Vol. 36, No. 138, pp.13-21.

Flugel, E., 1982. Microfacies of Limestone, Christenson, K. (Translator), SpringerVerlag, Berlin, 633p.

Flugel, E., 2004. Microfacies of Carbonate Rock, Analysis, Interpretation and Application. Springer-Verlag, Berlin, 976p.

Flugel, E., 2010: Microfacies of Carbonate Rocks, Analysis, Interpretation and Application, (2nd ed.), Springer - Verlag, Berlin, Heidelberg, 984 p.

Illing, L. V., Wells, A. J. and Taylor, J.C.M. 1965. Penecontemporary dolomite in the Arabian Gulf, In: Pray, A.C. and Murray, (eds.): Dolomitization and limestone diagenesis, SEPM, Spec. Pup., No. 13, pp. 71-88.

Jassim, S. Z. and Buday, T., 2006 a. Unit of the Unstable Shelf and the Zagros Suture, In: Jassim, S. Z, and Goff, J. C. Geology of Iraq,Published by Dolin Prague and Moravian Museum, Brno, pp. 71 - 83.

Jassim, S.Z. and Buday, T., 2006b. Late Tithonian-Early Turonian Megasequence AP8: In Jassim, S.Z. and Goff, J.C. (eds) Geology of Iraq. Published by Dolin, Prague and Moravian Museum, Brno, pp. 124 - 140.

Murray, R.C., 1964. Preservation of Primary structures and fabrics in dolomite In:Imbril,J., eds. Approches to Paleoecology, New York, Wiley, pp.388-403.

Özkan, A.M. and Elmas, A., 2009. Petrographic characteristic of the Kiziloren(Upper Triassic-Lower Jurassic) in the Akpinar(Konya-Turkey) Area,Ozean Journal of Applied sciences, Vol. 2,No. 4, pp. 451 - 463.

Radike, B.M., and Mathis, R.L., 1980. On the formation and occurrence of Saddle dolomite, Journal of Sedimentary Petrology, Vol. 50, pp. 1409 - 1168.

Rameil, N., 2008. Early diagenetic dolomitization and dedolomitization of Late Jurassic and earliest Cretaceous platform carbonates: A case study from the 
Jura Mountains (NW Switzerland, E France), Published in Sedimentary Geology, Vol. 212, No. 1 - 4, pp. 70 - 85.

Randazzo, A.F. and Zachos, L.G., 1984. Classification and description of dolomitic fabric of rocks from the Floridan Aquifer, U.S.A. Sedimentary Geology, Vol. 37, pp. 151 - 162.

Shingaly, W., AL-Juboury,A., and Elias,M., 2013. Dolomite Texture in the Upper Cretaceous carbonate - hosted $\mathrm{Pb}$-zndeposite, Zakao, Northern Iraq, Arabian Journal of Geosciences, pp. 1 - 23.

Sibley, D.F. and Gregg, J.M. 1987. Classification of dolomite rock texture. Jounrnal of Sedimentary Petrology, Vol. 57, No. 6 , pp. 967 - 975.

Sibley, D.F., 1982. The origin of common dolomite fabrics, Clues from the Pliocene. Jounrnal of Sedimentary Petrology, Vol. 52, pp. 1087 - 1100.

Ward, W.C. and Halley, R.B., 1985. Dolomitization in a mixing zone of Near-Sea water composition, late Pleistocene, Northeastern Yucatan Peninsula. Jounrnal of Sedimentary Petrology, Vol. 55, No. 3, pp. 407 - 420.

Warren, J., 2000. Dolomite occurrence, evolution and economic important associations. Earth-Science Reviews, Vol. 52, pp. 1 - 81. 